\title{
Application of Failure Mode Effects Analysis (FMEA) Method and Fault Tree Analysis (FTA) Towards Health and Occupational Safety on Jetty Project, Gresik, Indonesia
}

\author{
Mohamad F.N. Aulady ${ }^{1 *}$, Felicia T. Nuciferani ${ }^{1}$, Satya B. Wicaksono ${ }^{1}$ \\ Institut Teknologi Adhi Tama Surabaya, Jalan Arief Rachman Hakim 100 Surabaya, 60117, Indonesia \\ *Corresponding author: mohamadaulady@itats.ac.id
}

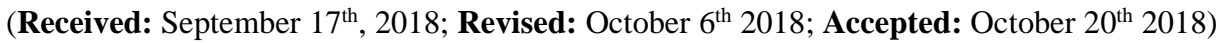

\begin{abstract}
Work accident in Indonesia has considerably increased every year. Work accident is often occurred in Construction sector. This is due to lack of proper occupational health and safety system (OHS). By the simple OHS management system, this issue can be improved. This research aim to identify the most fatal and high intensity risk of Jetty Project. Furthermore, this study also identify the risk cause that occur by simple method. Therefore, it will be easier for the company to do risk mitigation. To overcome this issue this research use Failure Mode Effect Analysis and Fault Tree Analysis methods. The results of this research show the most dominant risk priority in the girder bridge construction is the girder fall from during the mobilization. And daydream is the most dominant causes.
\end{abstract}

Keywords: Risk, Identification, Risk Causes

\section{Introduction}

Accident rate in Indonesia reached 95.624 cases in 2006, which improved to 96.324 in 2009 and significantly increased to 99.491 cases in 2011 [1]. Not only the rate accident increased tremendously, but the trend of workplace accident also tends to increase. Furthermore, Indonesia has to suffer from financial loss due to the high rate of workplace accident up to 190 billion in 2013 [2]. This condition gets even worse as only $2.1 \%$ out of 1.500 registered national companies implement the occupational health and safety system (OHS) [2]. This condition demands immediate and intensive improvement.

Unfortunately, construction sector is also the most vulnerable sector to workplace accident occurrence, noted at least $30 \%$ of cases of work accidents occurred in the construction sector [1]. In Indonesia, construction sector absorbs $7 \%$ to $8 \%$ of total employment or approximately 4.5 million workers [2]. It is known that $54 \%$ workers in this sector were primary school graduates [2]. This condition might be quite risky since construction sector demands workers' high skills in performing various professional jobs. In addition, this condition also appears as an obstacle in solving problems related to OHS in construction sector.

To enhance the implementation of OHS management in construction industry, an OHS staff in a company needs to be able to make analysis on various risks from occurrences in the past and determine the causes of the accident and design the most appropriate decision based on the experience. More importantly, a company also should be able to identify various risks and anticipate any occurrence of the risks. It is necessary to apply a simple and comprehensible method that make the implementation of OHS by companies easier. This research aim to identify the most fatal and high intensity risk of Jetty Project. Furthermore, this study also identify the risk 
cause that occur by simple method. Therefore, it will be easier for the company to do risk mitigation. To overcome this issue this research use Failure Mode Effect Analysis and Fault Tree Analysis methods.

Failure Mode and Effect Analysis (FMEA) is a method that can be used to evaluate the probability of failures or accidents within certain system [3], [4]. Meanwhile, Fault Tree Analysis (FTA) is a technique that is used to identify the failures within certain system and to find the causes of the failure [5], [6]. In this research, FMEA was employed to predict any accident that might occur in the future based on workers' experience in the past. FTA was also used to identify the causes of accidents that occurred in the past.

There are only few research that have been done using FTA and FMEA in construction sector. The use of FTA and FMEA is more common in Industrial sector. Putra [7] used FTA and FMEA to identify the causes of the defect in the hull construction of an oil product tanker motor boat namely KM. Pegerungan. From the result of the research, three main defects were found; missing bracket, missed weld and misalignment. While the FTA successfully identified the causes of the defects including the ones related to human errors and less optimal control process. In a different research, Mayangsari [8] used FTA and FMEA to improve the control over the quality of isolator production. The result of the research showed that there were 15 potential occurrences and 8 causes of faults. Hence, this research was conducted to evaluate and investigate a number of workplace accidents that occurred in Jetty construction project. This construction project was selected for it was considered to have relatively high risk as many heavy equipment were used during the project that demanded excellent human resources. The location of this project was in offshore.

\section{Literature Review}

\subsection{Failure Mode and Effect Analysis (FMEA) Concept}

FMEA is a method that is used to analyze component failures within a process or system, including analysis on the effects that might occur out of those failures (accidents) [3], [4]. FMEA process includes three main variables which are, Severity, Probability and Detection. Those three variables are then evaluated in the FME. The multiplication of those three factors determine the calculation of Risk Priority Number (RPN).

\subsection{Fault Tree Analysis (FTA) Concept}

FTA is a deductive method that is employed to identify the causes of faults using the top-down approach, by analyzing various unwanted occurrences or loss [9]. The causes of those occurrences are then identified and described in the form of a fault-tree. FTA approach uses various symbols to make connection among occurrences or activities. The symbol are shown in Fig. 1.

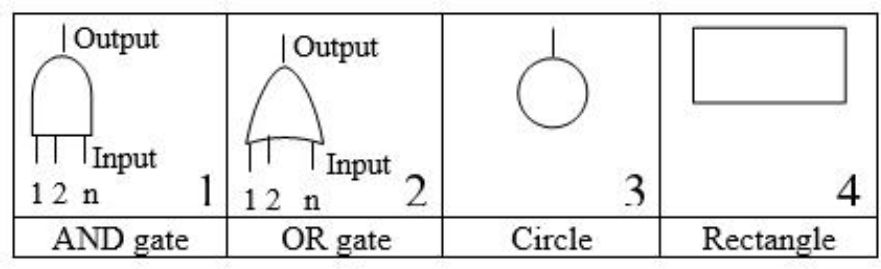

\section{Fig. 1 FTA Symbol [6]}

Some symbols are used in the FTA analysis to show the connection between certain occurrences to others that will lead to the top occurrence. Symbols that describe certain correlation include [6] :

1. Gate AND, showing a condition in which every occurrence that happens below the gate (input occurrence) is predicted to have certain contribution to the occurrences above the gate 
(output occurrence). In another word, output occurrences will take place if all input occurrences happen at the same time.

2. OR gate, showing a condition in which one or some occurrences below the gate (input occurrence) move to the ones above the gate (output occurrences). In another word, output occurrence occur if only one or several input occurrences take place.

Whereas, symbols that indicate an occurrence include:

1. Rectangular, referring to the main block for the tree analysis. It indicates negative occurrences above the tree, or they can also be put in any part of the tree to show other occurrences that need further analysis. The symbol is closely related to the gate of logic and the input occurrences below the gate.

2. Circle, indicating the basic occurrences in the tree. It is located beneath the tiered rows of the tree, showing that the occurrences need no further development or detailed explanation as there is no more occurrences or gates following.

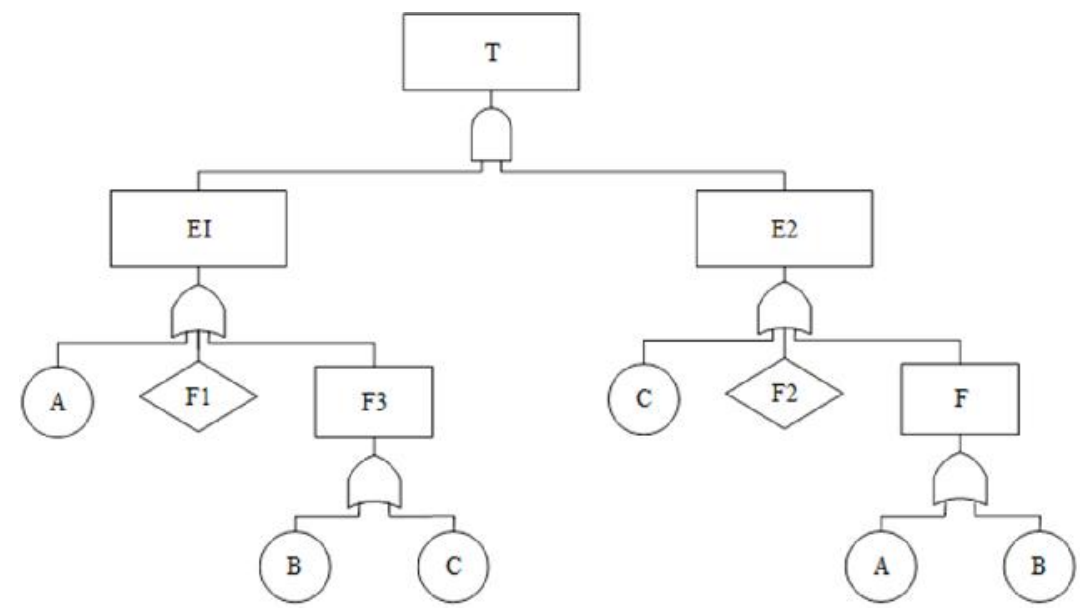

Fig. 2 The Illustration of FTA [6]

\section{Methodology}

This research started as the researchers started to collect research data including the primary and the secondary data. Before conducting FMEA and FTA, a validity test was administered to ensure the validity of the instruments towards the research objectives. The second step was analysis on the FMEA method, results of the interviews and distribution of the research questionnaires to measure the risk variables which had been previously identified, validated. Besides, RPN has also been analyzed. RPN value was obtained based on the level of probability, severity and detection. The third step was the FTA analysis which was conducted to determine the process of combination among factors that cause various workplace accidents as seen from the highest RPN average score. The analysis was done top down, starting from the top event which had been analyzed based the risk priority, up to the occurrences in the lowest rank, resulting in the determination of the most fundamental potentials that cause workplace accidents.

\section{Discussion}

\subsection{Failure Mode and Effect Analysis (FMEA)}

FMEA method was employed to analyze the potential of failures within certain system. In this step, RPN analysis was conducted, in which the RPN value was calculated by multiplying the values of probability, severity, and detection of each occurrence of the risk variable. Meanwhile, the three values were then analyzed by calculating the average scores of the questionnaire results 
in each segment. The results of the analysis on the probability (P), severity (S) and detection (D) values were then used to measure the RPN value of each failure mode. RPN value was obtained by calculating the average score of the total RPN. If the RPN was found greater than the average RPN (critical RPN), the job is categorized a risky or critical job.

Probability, severity and detection are from the questionnaire to the OHS expert in Jetty Company which is then processed to become RPN value. In this research, 5 jobs were analyzed and chunked into 15 details. From the 15 details, there were 55 modes of failure which became the main concerns. Out of 5 main jobs, only 2 jobs were categorized critical including the roadworks and girder bridge works there shown in

Table 1.

The RPN value of girder bridge job was found at 26.23 and the average RPN (critical RPN) was 24.23 , indicating that advanced RPN should be conducted in this matter. Advanced RPN analysis is a follow up analysis that is conducted to jobs that obtain severe criticality in order to find out the details of the jobs that also have alarming level of criticality. In this research, this analysis was done to make it easier for the researcher to identify the source of each problem in a systematic way. The overview of advanced FMEA analysis results is presented in Error! Reference source not found.

Aspects that needed immediate improvement are identified from the risk priority level as presented in

Table 1. It can be seen that girder mobilization needs prioritized improvement based on the fault modes in the girder bridge construction job. Girder mobilization job appears as the aspect that obtained the highest RPN (total RPN). The high RPN might was resulted from the high intensity of workplace accident that occurred in girder bridge construction job.

\subsection{Fault Tree Analysis (FTA)}

After we get the most risk factor, we then analyze the factor using FTA to obtain the risk cause. FTA employs a top-down deductive approach. Deductive approach analyses the general aspects first before going to the details or more specific aspects in order to eliminate irrelevant aspects one by one. The first step in conducting FTA done in this study was determining the top event.

Based on the results of FMEA and advanced FMEA, the top event fault was the fall of girder during the mobilization. It is also supported by the real condition on site where girder often falls during the mobilization process, making it as the top fault that often occurs in the project. Interviews conducted in this research show 4 factors affecting the first-level intermediate event which are; Personal Factor, Managerial Factor, Technical and Tool-Related Factor, and Environmental Factor

Table 1 Critical Risk Assessment

\begin{tabular}{|c|c|c|c|c|c|c|c|c|c|}
\hline \multirow{2}{*}{$\begin{array}{c}\text { Type of } \\
\text { work }\end{array}$} & \multirow{2}{*}{$\begin{array}{c}\text { Job } \\
\text { description }\end{array}$} & \multirow{2}{*}{ Failure Mode } & \multicolumn{3}{|c|}{ Risk Assessment } & \multirow{2}{*}{$\mathbf{R P N}$} & \multirow{2}{*}{$\begin{array}{l}\text { RPN } \\
\text { Total }\end{array}$} & \multirow{2}{*}{$\begin{array}{c}\text { Critical } \\
\text { RPN }\end{array}$} & \multirow{2}{*}{ Annotation } \\
\hline & & & $\mathbf{P}$ & $\mathbf{S}$ & D & & & & \\
\hline \multirow{4}{*}{ Roadworks } & \multirow{2}{*}{$\begin{array}{l}\text { Measurement } \\
\text { and pegging }\end{array}$} & $\begin{array}{l}\text { Slip due to the location of } \\
\text { the steep project }\end{array}$ & 2.93 & 2.13 & 2.53 & 15.85 & \multirow{4}{*}{25.81} & \multirow{4}{*}{24.23} & \multirow{4}{*}{ Critical } \\
\hline & & $\begin{array}{l}\text { Hit by a Vehicle around } \\
\text { which it is operating }\end{array}$ & 2.80 & 2.73 & 3.40 & 26.02 & & & \\
\hline & \multirow[b]{2}{*}{$\begin{array}{c}\text { Soil } \\
\text { Excavation }\end{array}$} & Explosion due to gas leak & 2.73 & 3.67 & 3.40 & 34.08 & & & \\
\hline & & $\begin{array}{l}\text { Electric short circuit due } \\
\text { to damaged cable and } \\
\text { leaking pipe }\end{array}$ & 3.00 & 3.40 & 3.20 & 32.64 & & & \\
\hline
\end{tabular}




\begin{tabular}{|c|c|c|c|c|c|c|c|c|c|}
\hline \multirow{10}{*}{$\begin{array}{l}\text { Type of } \\
\text { work }\end{array}$} & \multirow{5}{*}{$\begin{array}{c}\text { Job } \\
\text { description }\end{array}$} & \multirow{2}{*}{ Failure Mode } & \multicolumn{3}{|c|}{ Risk Assessment } & \multirow{2}{*}{ RPN } & \multirow{10}{*}{$\begin{array}{l}\text { RPN } \\
\text { Total }\end{array}$} & \multirow{10}{*}{$\begin{array}{c}\text { Critical } \\
\text { RPN }\end{array}$} & \multirow{10}{*}{ Annotation } \\
\hline & & & $\mathbf{P}$ & $\mathbf{S}$ & D & & & & \\
\hline & & $\begin{array}{l}\text { Fall into the Excavation } \\
\text { area }\end{array}$ & 2.53 & 3.13 & 2.93 & 23.28 & & & \\
\hline & & Landslide / collapse & 3.13 & 3.33 & 3.33 & 34.81 & & & \\
\hline & & Inhalation of dust & 3.93 & 2.13 & 2.67 & 22.38 & & & \\
\hline & $\begin{array}{c}\text { Backhoe } \\
\text { Placement }\end{array}$ & $\begin{array}{l}\text { The road around the } \\
\text { machine is in danger }\end{array}$ & 3.20 & 2.13 & 3.00 & 20.48 & & & \\
\hline & \multirow{2}{*}{$\begin{array}{l}\text { Land Back } \\
\text { Dewatering }\end{array}$} & $\begin{array}{l}\text { Affected by bucket } \\
\text { movement }\end{array}$ & 2.60 & 2.67 & 3.20 & 22.19 & & & \\
\hline & & Landslide / collapse & 3.67 & 3.00 & 3.13 & 34.47 & & & \\
\hline & \multirow{2}{*}{$\begin{array}{c}\text { Soil } \\
\text { Compaction }\end{array}$} & Machine overheated & 2.60 & 2.60 & 3.20 & 21.63 & & & \\
\hline & & Dehydration & 2.73 & 2.73 & 2.93 & 21.92 & & & \\
\hline \multirow{22}{*}{$\begin{array}{l}\text { Girder } \\
\text { Bridge } \\
\text { Works }\end{array}$} & \multirow{3}{*}{$\begin{array}{c}\text { Bridge } \\
\text { Location } \\
\text { Preparation }\end{array}$} & Impaled & 2.33 & 2.67 & 2.93 & 18.25 & \multirow{15}{*}{26.23} & \multirow{15}{*}{24.23} & \multirow{15}{*}{ Critical } \\
\hline & & Scratched & 28.7 & 3.07 & 2.67 & 23.44 & & & \\
\hline & & Dropped & 2.73 & 2.93 & 2.60 & 20.85 & & & \\
\hline & \multirow{6}{*}{$\begin{array}{c}\text { Girder } \\
\text { Mobilization }\end{array}$} & $\begin{array}{l}\text { Girder fell at the time of } \\
\text { mobilization }\end{array}$ & 2.33 & 3.40 & 3.67 & 29.09 & & & \\
\hline & & $\begin{array}{l}\text { Damage to the girder } \\
\text { (trailer) }\end{array}$ & 2.80 & 2.53 & 3.73 & 26.48 & & & \\
\hline & & $\begin{array}{l}\text { The safety chain is } \\
\text { broken / detached }\end{array}$ & 2.60 & 3.27 & 3.40 & 28.88 & & & \\
\hline & & Girder struck & 2.60 & 3.53 & 3.93 & 36.13 & & & \\
\hline & & Crushed sling cranes & 2.47 & 3.40 & 3.80 & 31.87 & & & \\
\hline & & Material arrives late & 3.47 & 2.73 & 3.00 & 28.43 & & & \\
\hline & \multirow{5}{*}{$\begin{array}{l}\text { Girder Bridge } \\
\text { Installation }\end{array}$} & Crane sank or collapsed & 2.27 & 2.73 & 3.53 & 21.89 & & & \\
\hline & & Sling broke while lifting & 2.53 & 3.13 & 3.27 & 25.93 & & & \\
\hline & & Shackle slipped off & 2.20 & 2.60 & 3.33 & 19.07 & & & \\
\hline & & Equipment damage & 2.60 & 2.80 & 3.33 & 24.27 & & & \\
\hline & & Grabs, fatality & 2.67 & 3.20 & 3.20 & 27.31 & & & \\
\hline & \multirow{8}{*}{$\begin{array}{l}\text { Transfer girder } \\
\text { to barge }\end{array}$} & $\begin{array}{l}\text { Sandwiched / Wrapped } \\
\text { during lifting and loading }\end{array}$ & 2.60 & 3.20 & 3.33 & 27.73 & & & \\
\hline & & Sling broke while lifting & 2.53 & 3.40 & 3.27 & 28.14 & & & \\
\hline & & Shackle apart / broken & 2.40 & 3.07 & 3.60 & 26.50 & & & \\
\hline & & Worker slips / falls & 3.07 & 3.07 & 2.87 & 26.96 & & & \\
\hline & & Feet pinched & 2.73 & 3.20 & 2.87 & 25.07 & & & \\
\hline & & $\begin{array}{l}\text { Hand scraped metal } \\
\text { objects }\end{array}$ & 2.87 & 2.60 & 2.53 & 18.88 & & & \\
\hline & & $\begin{array}{l}\text { Draws that are fatal / } \\
\text { defective }\end{array}$ & 2.53 & 3.47 & 3.27 & 28.69 & & & \\
\hline & & Material collapse & 2.40 & 4.00 & 3.47 & 33.28 & & & \\
\hline
\end{tabular}

Based on those factors, follow up interviews were administered to analyze the second-level and the basic event. Respondents shared their experience and they mentioned some aspects that contribute to the occurrence of personal factors including recklessness, inadequate skill, and stress. They also stated that limited time for debriefing and few number of OHS workers in the project trigger problems related to the managerial factors. For the technical and tool-related factors, all respondents agreed that the lack of knowledge about the operational procedure and the faults that come from the tools caused the problems in this category. Related to the environmental factor, the board of managers agreed that the main problem was the poor quality of the road and ever- 
changing weather were the event that ranked second. Based on respondents' statement, an FTA diagram was created.

It can be drawn into conclusion from the results of the FTA that there are 16 basic events from the four factors that cause girder to fall during the mobilization process. Within the personal factor category, day dreaming, rush, lack of motivation and fatigue are the main causes of the fault. In the management factor, lack of communication with OHS party, or communication between operators and support staffs, limited number of OHS workers and limited security time are found as the triggers. Third, the main aspects that trigger various technical and tool-related problems include the worn out tools, reluctance to wear protective equipment, disobedience towards the procedure, and inadequate knowledge on the function of certain equipment. The fourth factor, the environmental factor is influenced by several basic causes such as strong wind/ storm, extreme temperature, poor lighting, and the road characteristics.

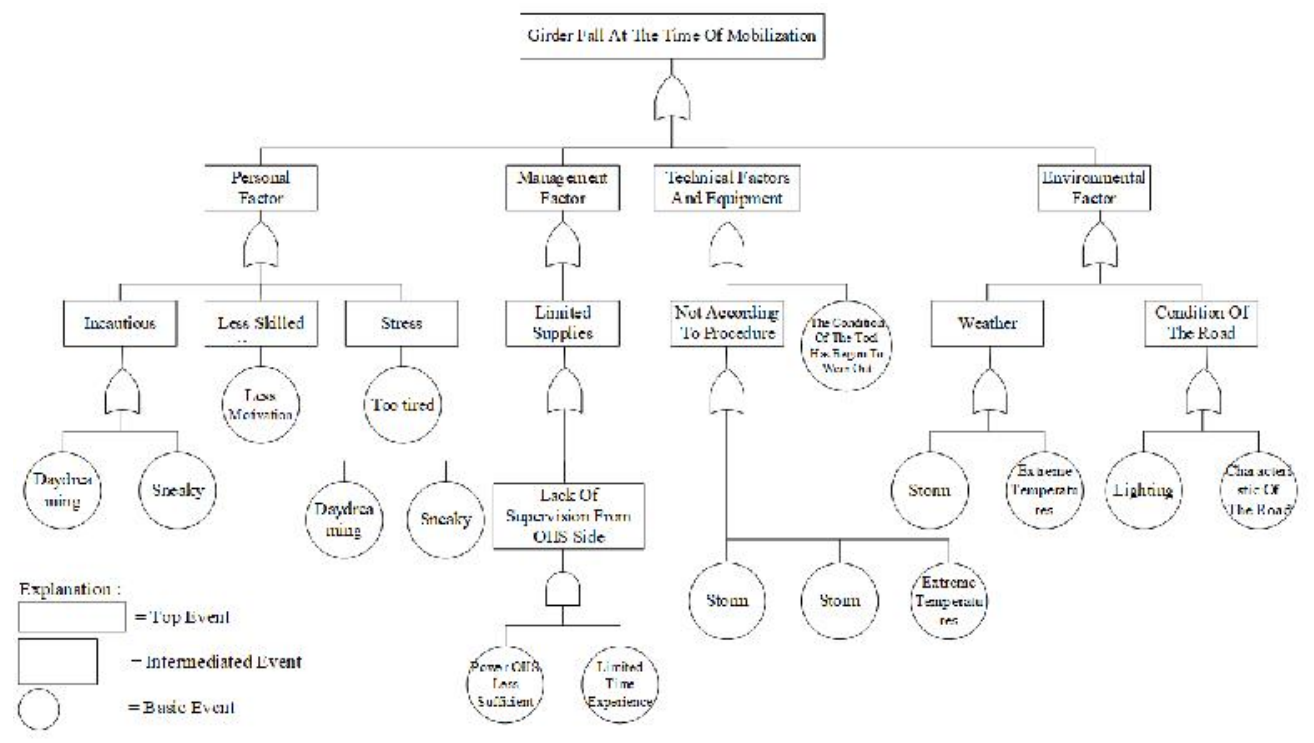

Fig. 3 FTA for girder fall at time of mobilization

\subsection{The combination of basic event and minimal cut set}

Minimal Cut Set was measured using the Method for Obtaining Cut Sets (MOCUS) followed by the completion of the FTA diagram measurement. MOCUS was employed to identify the effects of the combination of some risk sources that led to the top risk. These followings are the steps in determining the MOCUS:

1. Fig. 3 has been completed with several codes that made it easier for researcher to analyze the data. The top event was marked with letter I, while the intermediate event was marked with letters A, B, C, etc., and the basic event was marked with numeric symbols 1, 2, 3, etc.

2. Initiated by opening the top event gate, such as the mode of girder fall during the mobilization. The "girder fall during the mobilization" was opened as the gate I (Gi), which would be followed by codes written in order such as GA, GB, GC, etc. The accident of girder fall during the mobilization was marked or stated as a gate, indicating that the accident was a top event that has not inter-correlation with the intermediate event and at least one input event occurred. On the contrary, when the event was correlated with gate, then the codes were equally written as they were inter-correlated and all inputs occurred at the same time.

3. Gate was opened in order from the left to the right up to the basic event. Every unopened gate would be written again underneath. 
4. Every opened numbers were also re-written in every opened gate.

5. All gates had to be opened to show all of the numbers as well as the basic event as illustrated by the Figure.

6. Table 2 shows the results of MOCUS which were put into the table of minimal cut set.

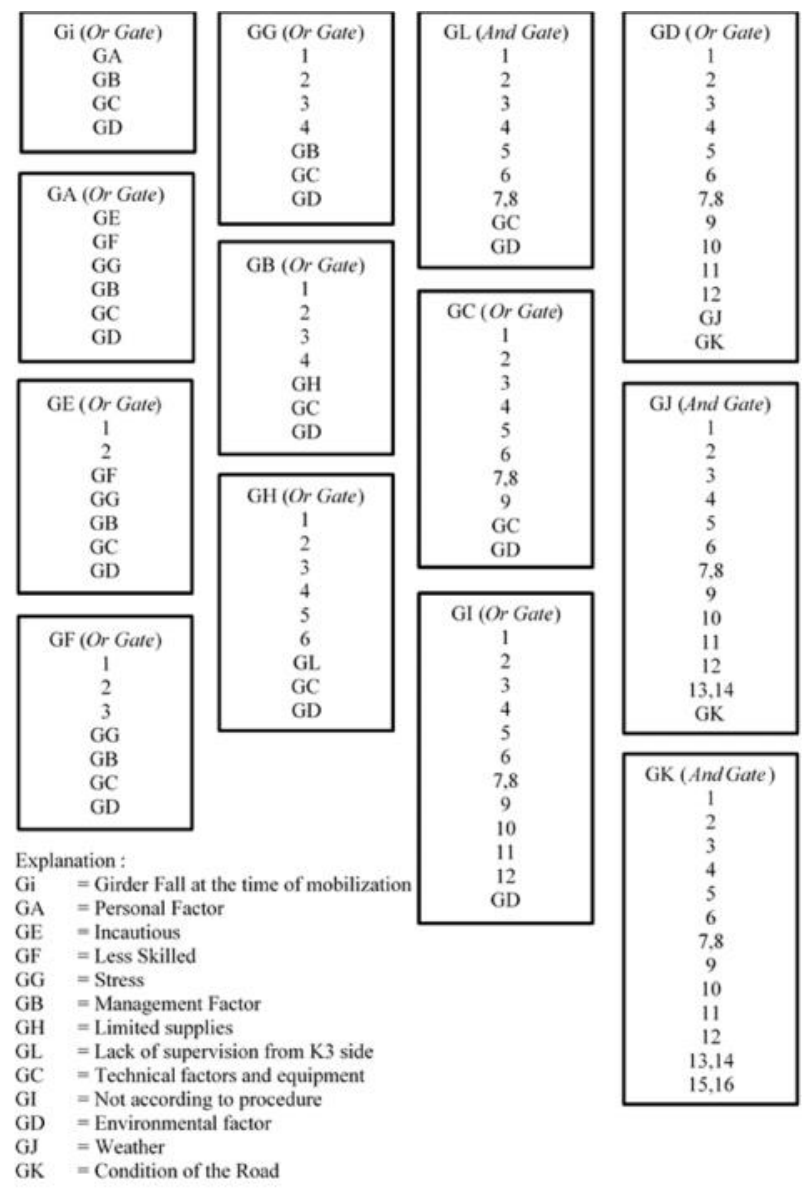

Fig. 4 MOCUS Girder falls during mobilization

Table 2 Minimal cut set for Jetty Project PT. Kias Manyar Gresik

\begin{tabular}{cl}
\hline & \multicolumn{1}{c}{ Minimal Cut Set } \\
\hline 1 & Daydreaming \\
\hline 2 & In a hurry \\
\hline 3 & Less motivation \\
\hline 4 & Too tired \\
\hline 5 & Less communication with OHS party \\
\hline 6 & Lack of operator communication with rigger \\
\hline 7,8 & OHS staff is not sufficient, Security time is limited \\
\hline
\end{tabular}




\begin{tabular}{cl}
\hline 9 & The condition of the tool has started to wear out \\
\hline 10 & No safety \\
\hline 11 & Disobeying usage rules \\
\hline 12 & Do not understand the function of the tool \\
\hline 13,14 & Wind / Storm, Temperature extremes \\
\hline 15,16 & Lighting, Street Characteristics \\
\hline
\end{tabular}

It can be seen from the FTA and the combination between Basic Event and Minimal Cut Set that the cause of the accident girder fall during the mobilization is the day dream and rush, while workers' lack of motivation and fatigue are known as the supporting factors. By understanding the main cause of the OHS problems in this Jetty Project, it is expected that the management of the project prepare appropriate preventive actions before another accident occurs.

It is stated in a research that one day dreams due to several reasons. Just about every thought that people have is related directly or indirectly to one of their goals. Most of these goals are extremely basic and many of them are short-term. Like trying to remember to buy tomatoes on the way home or worrying about what you're going to say to somebody. But the frequency with which many of us daydream estimates suggest that up to half of our waking lives are spent daydreaming [10]. Another fact about daydreaming is that people were less happy when their minds were wandering.

From this insight, project managers should be able to design and implement proper preventive measures to decrease workers' tendency to daydream while performing their work. The measure should be implemented by the time workers arrive at work. The management may create fun atmosphere for the workers in the workplace. Thus, their sadness would not disrupt their minds during the work. Safe and comfortable workplace are also able to decrease the daydreaming tendency. Casual morning safety talk (with some jokes) will create relaxing atmosphere that lightens up the mood and improves workers' concentration.

\section{Conclusion}

The results of this research show 86 relevant variables which could potentially be the risks of workplace accidents in the jetty construction project held by PT. Kias Manyar Gresik. Those 86 variables were derived from 5 different jobs with 25 sub-items in the project. The highest RPN was found in the girder bridge construction job. The most dominant risk priority in the girder bridge construction is the girder fall from during the mobilization at 30.15. Item of job with the most dominant risk priority should be identified in order to identify the causes of its top event.

4 factors have been identified as the sources that cause the accident risk which are personal factor, managerial factor, technical and tool-related factor and environmental factor. Out of those factors, 16 basic events have been determined using the MOCUS method which could be grouped into 13 basic events. It is known that workers' daydream is the most dominant top event. Hence, the management of the company should take certain action to prevent this problem from occurring by creating favorable workplace that decreases workers' tendency to daydream while performing their job. Future researchers are encouraged to investigate the most effective ways to keep workers pleased in the workplace in order to prevent them from daydreaming at work.

\section{References}

[1] H. Pritanti, Purwoto, and Solechan, "Criminal Accountability Against Contractors In the event of Work Accident Under Law No. 3 of 1992 on Social Security of Labor," Diponegoro Law Rev., vol. 1, no. 4, 2012.

[2] R. Wirahadikusumah, "The Challenge of Occupational Safety and Health Issues on Construction Projects in Indonesia.". 
[3] S. Kmenta, P. Fitch, and K. Ishii, "Advanced Failure Modes And Effects Analysis Of Complex Processes," in Proceding of the 1999 ASME Design Enginering Technical Conferences, Las Vegas, Nevada, 1999, pp. 1-9.

[4] S. J. Rhee and K. Ishii, "Life Cost-Based FMEA Incorporating Data Uncertainty," in 7th Design for Manufacturing Conference, Montreal, Quebec, Canada, 2002, vol. 3, pp. 309-318.

[5] S. P, D. Pudjotomo, and T. Tifani, "Cause Analysis Of Downloading Of Competitive Milk Dairy Products On Milk Import Milk On Milk Processing Industry (MPI) With Fault Tree Analysis (FTA) And Barrier Analysis Method," J@ti Undip J. Tek. Ind., vol. 4, no. 2, pp. 71-80, May 2011.

[6] Faisal and M. Fitria, "The Use Of Boolean Aljabar In Analysis Of Fault Tree Analysis Failure," J. Appl. Pure Math., vol. 3, no. 2, pp. 27-38, Dec. 2009.

[7] M. N. M. Putra, I. P. Tama, and Z. Darmawan, "Defect Cause Analysis on Hull Construction (HC) of KM. Pagerungan with Failure Mode and Effect Analysis (FMEA) and Fault Tree Analysis (FTA) (Case study in PT. PAL Indonesia)," J. Eng. Manag. Ind. Syst., vol. 3, no. 2, pp. 291-300, 2015.

[8] D. F. Mayangsari, H. Adianto, and Y. Yuniati, "Proposed Control Of Isolator Quality Products With Failure Mode And Effect Analysis (FMEA) And Fault Tree Analysis (FTA)," Online J. Natl. Inst. Technol., vol. 3, no. 2, pp. 81-91, Apr. 2015.

[9] V. C. Gerogiannis, I. E. Caragiannis, and M. A. Tsoukarellas, "A general framework for applying safety analysis to safety critical real-time applications using fault trees," in Proceedings Ninth Euromicro Workshop on Real Time Systems, 1997, pp. 168175.

[10] M. A. Killingsworth and D. T. Gilbert, "A Wandering Mind Is an Unhappy Mind," Science, vol. 330, no. 6006, pp. 932-932, Nov. 2010. 